\title{
The use of Virtual Reality and physical tools in the development and validation of ease of entry and exit in passenger vehicles
}

Glyn Lawson $^{\mathrm{a}}$, Paul Herriotts ${ }^{\mathrm{b}}$, Louise Malcolm ${ }^{\mathrm{b}}$, Katharina Gabrecht ${ }^{\mathrm{a}}$, Setia Hermawati ${ }^{\mathrm{a}}$

${ }^{a}$ Human Factors Research Group, Faculty of Engineering, The University of Nottingham, United Kingdom

${ }^{\mathrm{b}}$ Jaguar Land Rover, Gaydon, Warwickshire, CV35 ORR

Corresponding author: glyn.lawson@nottingham.ac.uk

Coates B72, Faculty of Engineering, University Park, The University of Nottingham, NG7 2RD $+44(0) 1159514003$

\begin{abstract}
Ease of entry and exit is important for creating a positive first impression of a car and to increase customer satisfaction. Several methods are used within vehicle development to optimise ease of entry and exit, including CAD reviews, benchmarking and buck trials. However, there is an industry trend towards digital methods to reduce the costs and time associated with developing physical prototypes. This paper reports on a study of entry strategy in three properties (buck, car, CAVE) in which inconsistencies were demonstrated by people entering a vehicle representation in the CAVE. In a second study industry practitioners rated the CAVE as worse than physical methods for identifying entry and exit issues, and having lower perceived validity and reliability. However, the resource issues associated with building bucks were recognised. Recommendations are made for developing the CAVE and for combinations of methods for use at different stages of a vehicle's development.
\end{abstract}

Keywords: entry exit, automotive

\section{Highlights:}

- Inconsistent entry strategies were observed in a CAVE virtual environment

- The CAVE needs development to support design for ease of entry and exit

- Representation of vehicular hard points is necessary for optimising entry and exit

- Various combinations of methods are required at different stages of vehicle development 


\section{Introduction}

Entering and exiting a vehicle are complex motions that require control and strength (Gransitzki 1994). These motions create high biomechanical stresses from bending, turning, twisting, stretching and leaning (Bhise, 2011). Previous research has shown that car designers and engineers need to pay particular attention to the ease of entry and exit for several reasons. This is firstly because vehicle entry is the initial interaction the customer has with the vehicle and is a key influence on purchasing decision (Causse et al., 2012; Tetlock, 1983; Zhan et al., 2013). Secondly, entry and exit requires attention due to the number of problems drivers have getting in and out of cars. In a large postal questionnaire survey of older and younger drivers in Great Britain, $25 \%$ of older drivers and $14 \%$ of younger drivers reported problems entering cars, while $32 \%$ of older and $18 \%$ of younger drivers reported problems getting out of cars (Herriotts, 2005). Thirdly, minimising the demands and stresses that occur on entry and exit can improve customer satisfaction (Herriotts \& Johnson, 2013). However, car design is a compromise between several vehicle attributes and entry and exit may not always be prioritised in the trade-off between packaging, styling, safety and other aspects (Koester and Hamilton, 1994). For example to improve off-road capability the step up height for a sports-utility vehicle (SUV) may be higher than optimal for customers when entering the vehicle; or the low roof of a sports car may cause customers to stoop or to drop down into the vehicle as priority is given to sports car styling and aerodynamics.

A variety of methods are used to assess the suitability of a design for the customer. These are described below in the vehicle development process. At the beginning the ergonomist sets dimensional targets to support ease of entry and exit. These targets are based on a numerical understanding and benchmarking of current and competitor vehicles. This initial 
data is then used to generate a "buck", an early basic physical model of the target vehicle (Figure 1). This can then be used for expert reviews and for user trials with participants representing the target population to validate and develop ease of entry and exit (Andreoni et al, 2004; Sternini and Cerrone, 1995). As the design develops, the quality and fidelity of the buck increases, followed by the production of a prototype vehicle, at which point the entry and exit condition can be validated with confidence. This traditional process is heavily reliant on physical properties that are expensive and time consuming to produce (Ait El Menceur et al, 2008; Laughery, 2005; Södermann 2005). In addition, traditional user trials with significant sized groups of people are cost and time intensive (Pudlo et al. 2006).

However, this process has been validated in numerous car companies and is known to result in vehicles that accommodate the range of drivers and passengers (Herriotts \& Johnson, 2013).

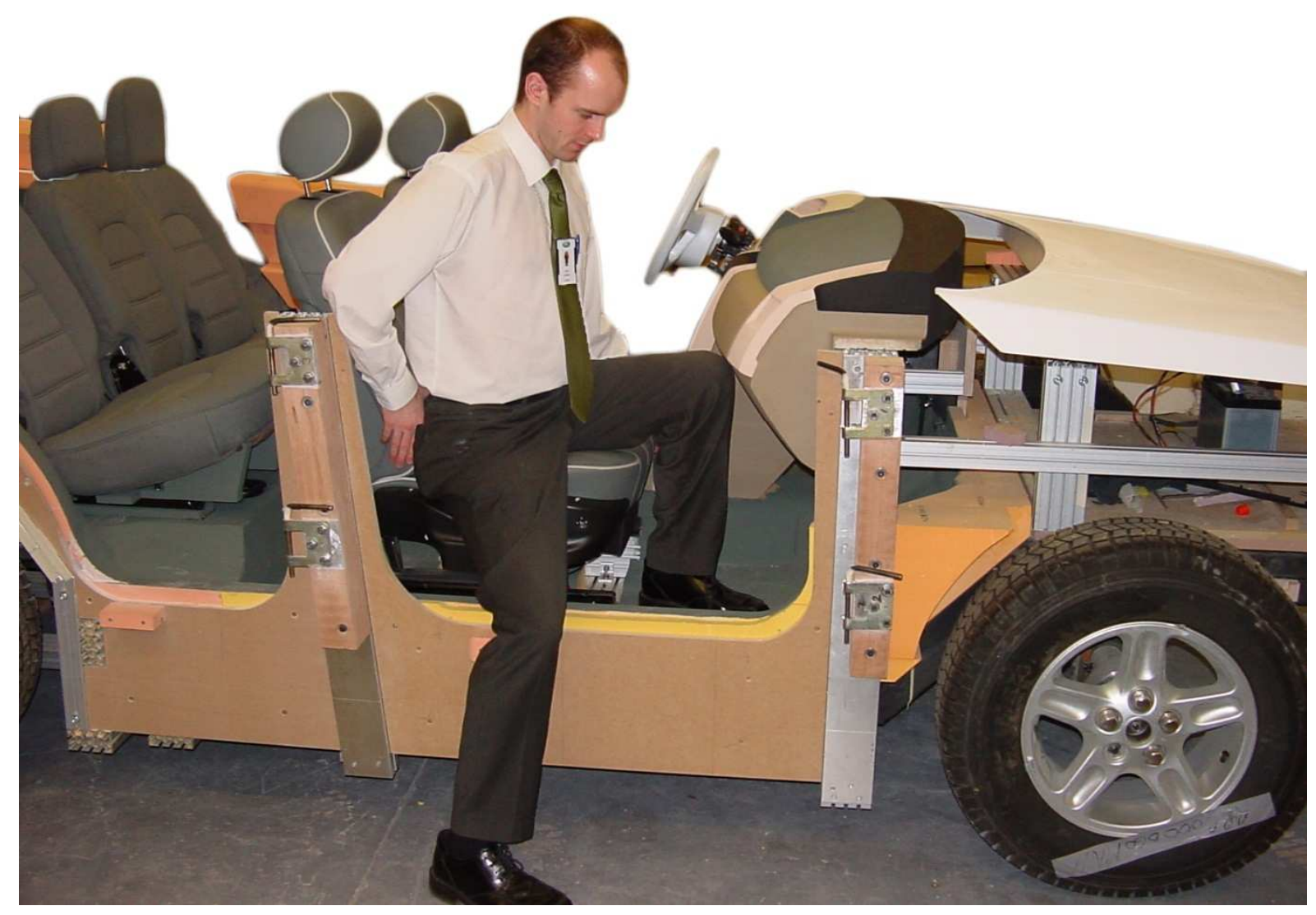


Figure 1. Vehicle buck - geometrically accurate representation of a vehicle. Bucks can be used to represent design targets or the current design intent. This image shows a passenger exiting a lefthand drive buck.

The vehicle development process is under increasing pressure as product life cycles are shortening and automotive manufacturers today are faced with the challenge of bringing new products to market in shorter intervals (Bernard et al., 2012; Schrader et al., 2002). To achieve these aims, it is critical to evaluate the customers' experience very early in the vehicle design process, which can also reduce the costs of design changes as the development cycle progresses (Laughery, 2005; Monnier et al, 2006). There is a general trend in design and engineering to reduce the total development costs and time by using computer aided engineering technologies. A robust virtual tool can reduce the need for expensive physical prototypes (Hanson et al, 2006; Jayaram et al, 2001). Furthermore, with virtual prototyping more design iterations are possible within a shorter time (Wang, 2002).

Digital vehicle models and digital human models are used to assess the ergonomics of vehicles during the early phases of design, providing simulation of the physical interactions between target customers and the vehicle (Chateauroux \& Wang, 2010). Digital Human Modelling (DHM) uses digital manikins that can be changed in size and shape to represent the target range of users. DHM is used throughout the automotive industry to evaluate driving position, vision, reach and posture, but has not traditionally been used for entry and exit. There has however been a recent focus on research into DHM for entry and exit (e.g. Chateauroux \& Wang, 2010; Cherednichenko et al., 2006; Kawachi et al., 2005; Monnier et al, 2006; Reed \& Huang, 2008). With DHM the manikin can be moved as a real person moves, but cannot reliably register discomfort or satisfaction. As entry and exit is a dynamic process, and as human behaviour is so complex, people vary in the movement strategies used when getting in and out of a vehicle. Currently DHM tools cannot predict these complex strategies. 
Monnier et al (2006) presented a DHM system for evaluating entry and exit using motion capture to digitise the movements of 23 people entering and exiting four different car models. They then identified the movement strategies used and significant vehicle parameters before applying an algorithm to simulate motion and subjective discomfort ratings for individuals and the subject population. However, Monnier et al.'s (2006) system lacks validation and further work is required on the discomfort prediction, which currently excludes dynamic parameters. Moreover, the system initially requires data capture from real people using bucks or cars, which may limit the benefits. Other authors have also had difficulty in using DHM to predict real world behaviour. Reed and Huang (2008) developed a framework for control of complex motions in DHM, such as entry and exit. While the authors were able to model different entry strategies using the framework, it lacked the ability to predict subjective responses. Reed \& Huang (2008) concluded that for DHM to be a valid tool there must be a documented relationship between kinematic or dynamic variables and subjective responses. This has not yet been validated for complex movements such as entry and exit.

In addition to DHM, Virtual Reality (VR) CAVEs are now being used in automotive design. A VR CAVE is a semi-immersive environment where images are projected on to three walls and the ceiling (Figure 2). A user wears 3D glasses to enable depth perception in the environment (Cruz-Neira et al, 1992). When the user moves in the CAVE, his or her head position is tracked in order to present the images in real-time and to provide the correct perspective (Rebelo et al. 2010). A CAVE has the advantages of a large field-of-view, freedom to look around, and a lack of intrusion from the interface (Cruz-Neira et al, 1992). However, accurate depth perception is essential for ergonomics assessments and subjective perceptions of distance have been reported to be less in virtual environments than those in the real world (Klein et al., 2009; Renner et al., 2013). This has been attributed to differences in measurement methods, technical factors (e.g. limited field of view, low rendering quality), 
compositional factors (e.g. rich or sparse virtual environment, use of texture) and human factors (e.g. experience with VR, sense of presence). Research to understand the impact of these differences on applications of virtual environments is lacking (Renner et al., 2013). Additionally, convergence/accommodation conflict can occur where visual objects in the CAVE appear at a variety of stereoscopic depths despite being presented on the screen at the same accommodation plane (Baitch and Smith, 2000). In addition to depth perception issues, this conflict can lead to visual discomfort or simulator sickness (Chen et al., 2014; Häkkinen et al., 2006; IJsselsteijn et al., 2000).

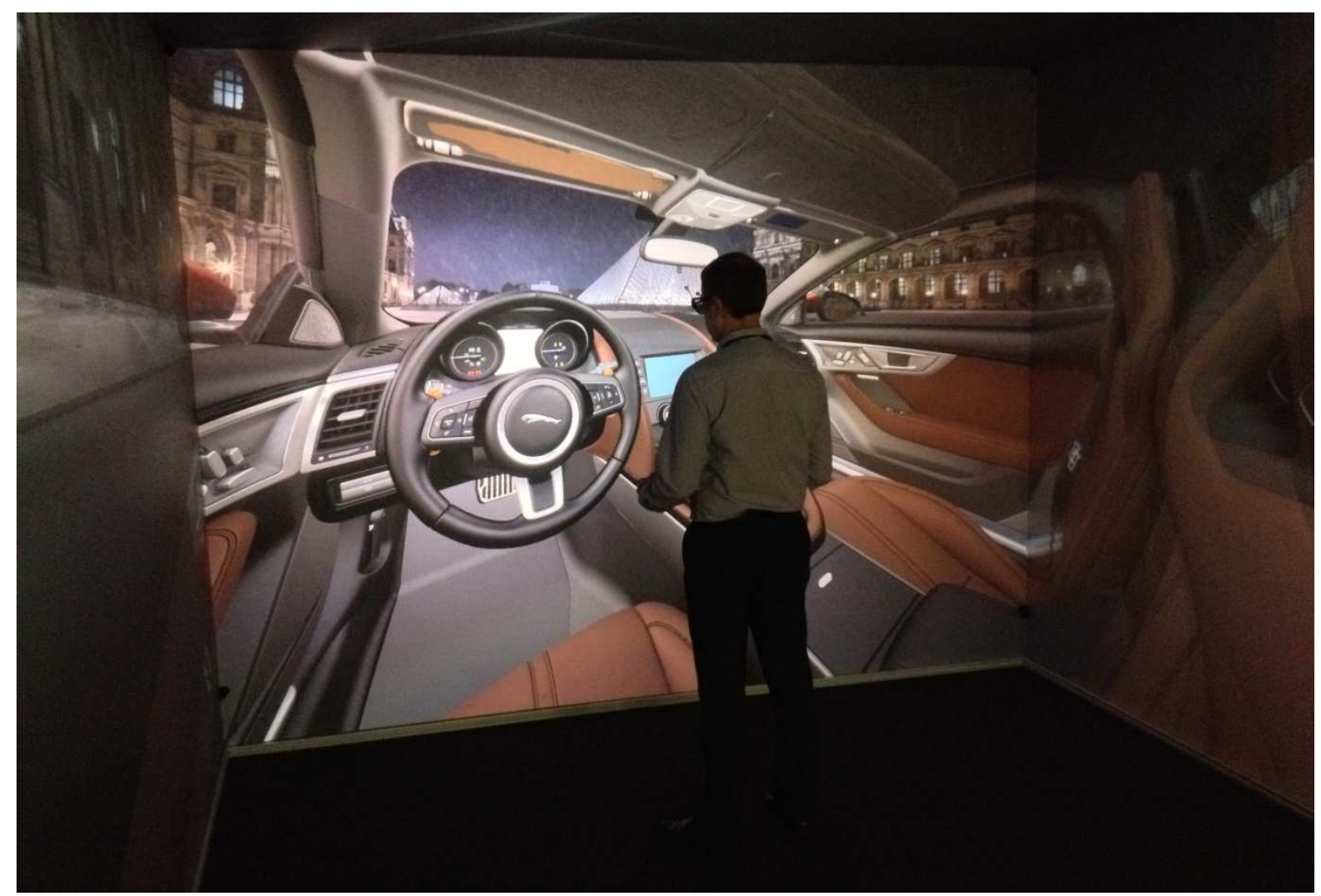

Figure 2. CAVE 3D stereoscopic environment

The use of CAVEs has been analysed in a number of applications including driving simulators (Kim et al, 2005; Mollenhauer et al, 2005) and other aspects of automotive ergonomics including reach and visibility (Reuding \& Meil, 2004). Reuding and Meil (2004) conducted a study to investigate the reliability of the CAVE for in-vehicle reach and visual task performance by comparing data against those obtained from a physical buck. They concluded that to obtain reliable results the CAVE must be used as a comparative tool, i.e. 
design option A vs. design option $B$, due to differences in performance between the CAVE and the real world.

While VR CAVEs are the subject of academic research (e.g. Juan \& Perez, 2009; Repperger et al., 2003; Whalstrom et al., 2010) little work has been done on their acceptability for entry and exit work by automotive industry professionals. For entry and exit activities to occur in a virtual world there must still be some hardware (e.g. steering wheel, pedals, and seat) as a participant cannot achieve a driving position in free space. The use of this hardware poses potential issues, such as depth perception differences between virtual and real objects as a result of accommodation conflicts in which the accommodation of the virtual image is always at the virtual display whereas accommodation of the physical object will be closer (Drascic and Milgram, 1996). Hardware may also cause obscuration of the virtual world, issues due to registration accuracy and accommodation errors, as found in previous research into the use of haptic devices represented in virtual environments (Olsson et al., 2012). Even the presence of the participant's own body in the virtual environments can cause occlusion issues (Bouguila et al., 2000), for example, the hand could obscure the virtual image of the cant rail, but the cant rail cannot obscure the hand, as it obviously would in the real world. Occlusion is considered by Drascic and Milgram (1996) as the strongest indicator of depth because of its dominance over all other cues. That is, despite any ambiguity in the environment, in the real world objects which are far away cannot obscure those which are closer. The impact of these issues on the use of CAVEs for optimising entry and exit is unknown. Finally, research in the field of virtual reality in automotive design has often focussed on validity (e.g. Dymott et al, 2003; Lorenz et al., 2008), which is only one criterion for the success of a measure (Wilson, 2005). Ergonomists have previously been criticised for accepting a method too readily without considering its merits (Annett, 2000). Other criteria include utility, resources and system stability (Reuding \& Meil, 2004) which are important to the success of any method. 
Importantly, the nature of the design process changes from concept to prototyping, therefore it is likely that more than one method has use for optimising entry and exit. To the knowledge of the authors, no work has analysed against a range of criteria, methods which may have use for optimising ease of entry and exit, nor looked at which tools should be used at different stages of the vehicle development process. Use of the methods is dependent upon their acceptability to industry practitioners.

\section{Objectives / research questions}

- To understand the utility of the CAVE for optimising vehicle entry and exit in comparison to a real car and to a "buck" - the current industry standard

- To investigate industrial practitioners'/stakeholders' perceptions of methods for optimising entry and exit

- To identify when in the vehicle development process tools for optimising entry and exit should be used.

\section{Study 1: External validity of methods for studying entry and exit}

As mentioned, little previous work has been conducted to investigate the utility of a CAVE for optimising ease of entry and exit. Therefore, the first study aimed to compare the entry experience of occupants using a CAVE 3D immersive stereoscopic environment with the corresponding real production car. That is, study 1 aimed to determine if a virtual reality CAVE is a valid tool for assessing ease of vehicle entry. Although the study focussed on ease of entry, the authors believe that the issues raised in the ease of entry study should be representative of both entry and exit.

As the current approach for optimising entry and exit within Jaguar Land Rover relies on vehicle bucks, this condition was also included in the study as a second comparison to the CAVE. While the buck is typically geometrically accurate to the design intent at the time of its construction, it uses materials which differ to the real car (e.g. wood rather than metal or 
plastic mouldings) - Figure 1. Thus, it was pertinent to assess the validity of both the CAVE and the buck as tools for optimising ease of entry and exit.

It is known that people enter cars using a number of strategies but that individuals display stability of strategy within a vehicle (Ait al Menceur et al, 2008; Johansson 2002; Rigel, 2005) and could change their strategy when entering a vehicle with a different geometry (Ait al Menceur et al, 2008; Cherednichenko et al., 2006). This stability of strategy would therefore be expected across a real car and a valid model of that car; i.e. CAVE or buck. The stability of entry method was used as an indicator of tool validity. In fact, many other measures (e.g. number of contact points) would be impossible to record consistently across the three different properties, particularly as the visualisation of the CAVE is regenerated based on the head position of the person wearing the tracked glasses and impact would therefore not be visible to an observer.

It was hypothesised that the ingress strategy of each participant remains the same across the physical vehicle and CAVE conditions for Car A, and the vehicle buck and CAVE conditions for Car B, and that individuals' ingress strategy remains the same within a condition.

\subsection{Method}

\subsubsection{Participants}

A total of 20 participants (14 male, 6 female) were recruited from Jaguar Land Rover employees. Participants held valid driving licences and were not directly involved in the development of the cars being evaluated. Mean age was 26.9 (range 20-53, SD = 8.48). Participant stature ranged from $1575 \mathrm{~mm}$ to1952 mm (mean = $1766 \mathrm{~mm}, \mathrm{SD}=105.4)$, mean weight was $77.1 \mathrm{~kg}$ (range 53.3-109.8kg, SD = 22.8).

\subsubsection{Apparatus}

The three tools used in the study are described below. 
- Virtual Reality CAVE: The HoloVis 4K CAVE is a virtual reality facility, comprising a space with three walls and a ceiling acting as screens on to which high resolution images are projected (Figure 2). Within this environment the architecture of the car is modelled with the addition of a physical seat and wheel. The seat is set at the appropriate vehicle height to ground. Participants wear stereo glasses with head trackers to see in $3 \mathrm{D}$ within the space. Representations of both a saloon car (Car A) and an SUV -Sports Utility Vehicle (Car B) were created in the CAVE.

- Physical buck: A buck is a physical model of a vehicle (Figure 1 shows a buck similar to that used for this trial; the actual buck used in the trial is commercially sensitive and therefore cannot be shown). While it is dimensionally accurate to design intent to within a few millimetres, it is manufactured of materials that are not representative of those in a car e.g. wood and foam. In this trial, a buck for the SUV (Car B) was used.

- Production car: A production car is a manufactured vehicle as offered for sale to the public. The product version of Car A was used in this trial.

All properties were left-hand drive to ensure consistency across conditions.

\subsubsection{Procedure}

Participants entered the driver's seat of the vehicle in four conditions; two conditions for Car A, (CAVE and a production car), and two conditions for Car B, (CAVE and physical buck).

The experimental design was chosen to reflect the extremes of car type produced by Jaguar Land Rover. Unfortunately the SUV and saloon cars were not available in all conditions: real car, CAVE \& buck; however, as the stability of entry strategy was the chosen measure of validity, this had minimal impact on the results.

Participants were first asked to set up the seat and steering wheel to their preferred driving position. Having done so, they then entered the vehicle two times. During this process they 
were videoed to enable post trial analysis. Each participant evaluated each of the four conditions.

The study received approval from The University of Nottingham Faculty of Engineering Ethics Committee.

\subsection{Results}

Post-trial postural analysis of the videos was undertaken to enable entry strategies to be classified. Entry strategies are generally divided into foot first or hip first movements (Ait al Menceur et al, 2008). To provide more detailed information entry strategies were classified into one of the four categories defined by Rigel (2005) and described in Table 1.

Table 1. Four strategies for entry (left-hand drive vehicles) (Rigel, 2005).

\begin{tabular}{|l|l|}
\hline Slip strategy & $\begin{array}{l}\text { The driver enters the car with their right leg first, keeping it on the left } \\
\text { hand side of the steering column. They then lower themselves into the } \\
\text { seat. When seated the left leg is lifted into the car and the right knee is } \\
\text { moved to the right side of the steering column. }\end{array}$ \\
\hline Thread strategy & $\begin{array}{l}\text { The driver enters the car with their right leg first and it is moved under } \\
\text { the steering wheel to position the foot in front of the accelerator pedal. } \\
\text { At the same time they lower themselves into the seat. Once seated the } \\
\text { left leg is moved into the car. }\end{array}$ \\
\hline Plump strategy & $\begin{array}{l}\text { The driver sits on to the seat while facing away from the vehicle. Once } \\
\text { seated the legs are lifted into the car. }\end{array}$ \\
\hline Hurdle strategy & $\begin{array}{l}\text { The head and right leg enter the car at the same time. The right foot is } \\
\text { moved in front of the accelerator pedal. }\end{array}$ \\
\hline
\end{tabular}

For both the production car and the physical buck the slip strategy was used by ninety percent of participants, with the other ten percent using the thread strategy. While the slip strategy was also the most common for the CAVE conditions, there was greater variation in entry methods used as shown in Figure 3. In the CAVE condition for Car B (SUV), thirty percent of participants used the hurdle strategy. 


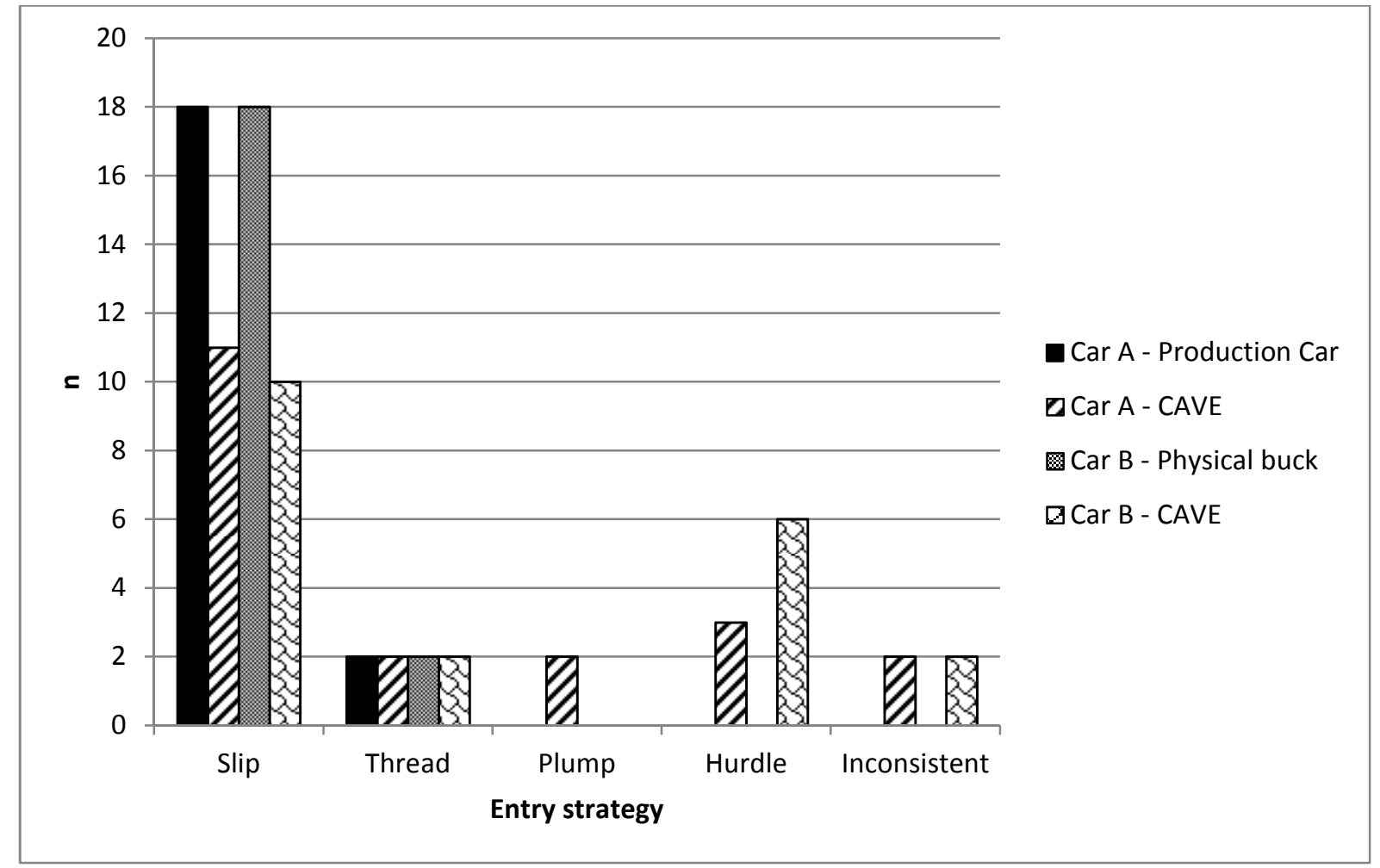

Figure 3. Number of participants adopting each entry strategy

To determine stability of the entry method a comparison was made of the strategies used in the physical and virtual conditions.

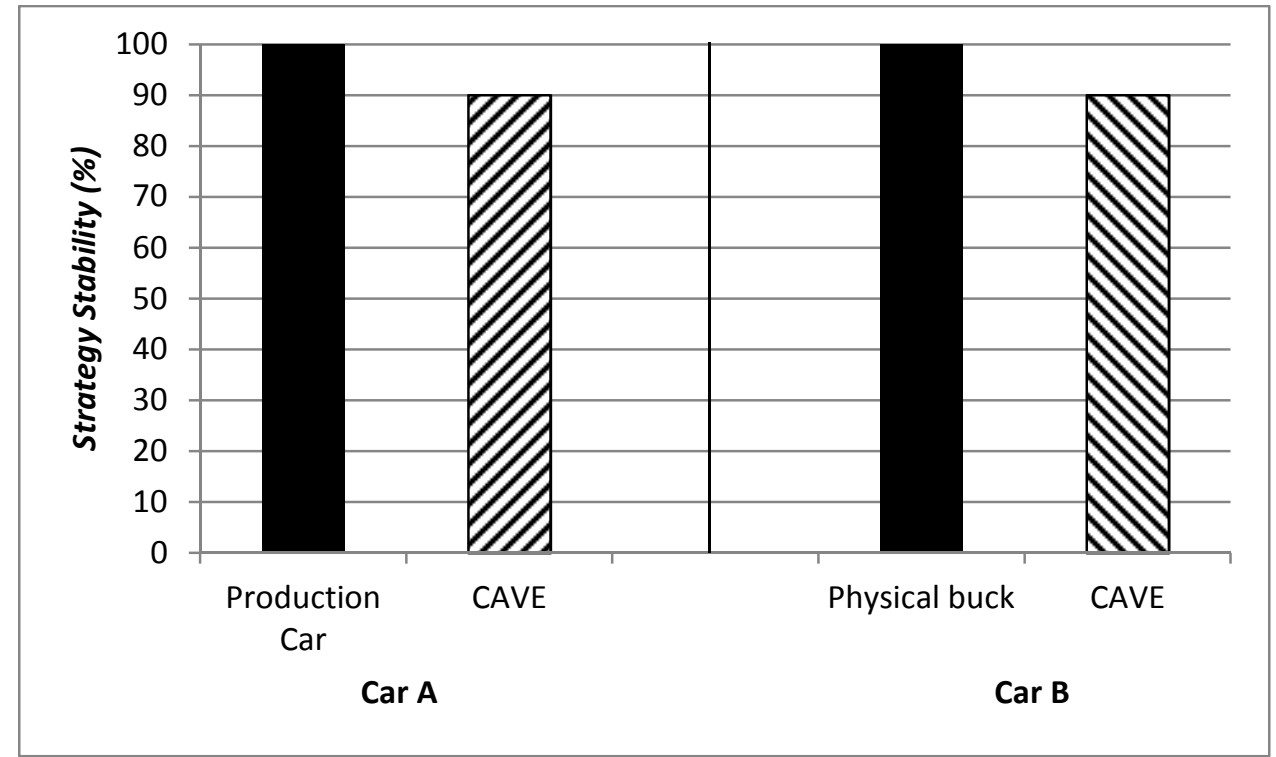

Figure 4 Percentage of participants who exhibited stability in entry strategies in each condition. 
Figure 4 shows that for both the Production Car A and Physical Buck Car B all of the participants were consistent in their entry strategies, while in CAVE conditions for Car A and Car B the majority were consistent $(\mathrm{N}=18)$. However while almost all were consistent within each condition, the strategies used often changed between the physical conditions and CAVE, with stability dropping to $60 \%$ and $55 \%$ for Cars A and $B$ respectively as shown in Figure 5. These results are indicative of a change in entry strategy stability between physical and virtual properties.

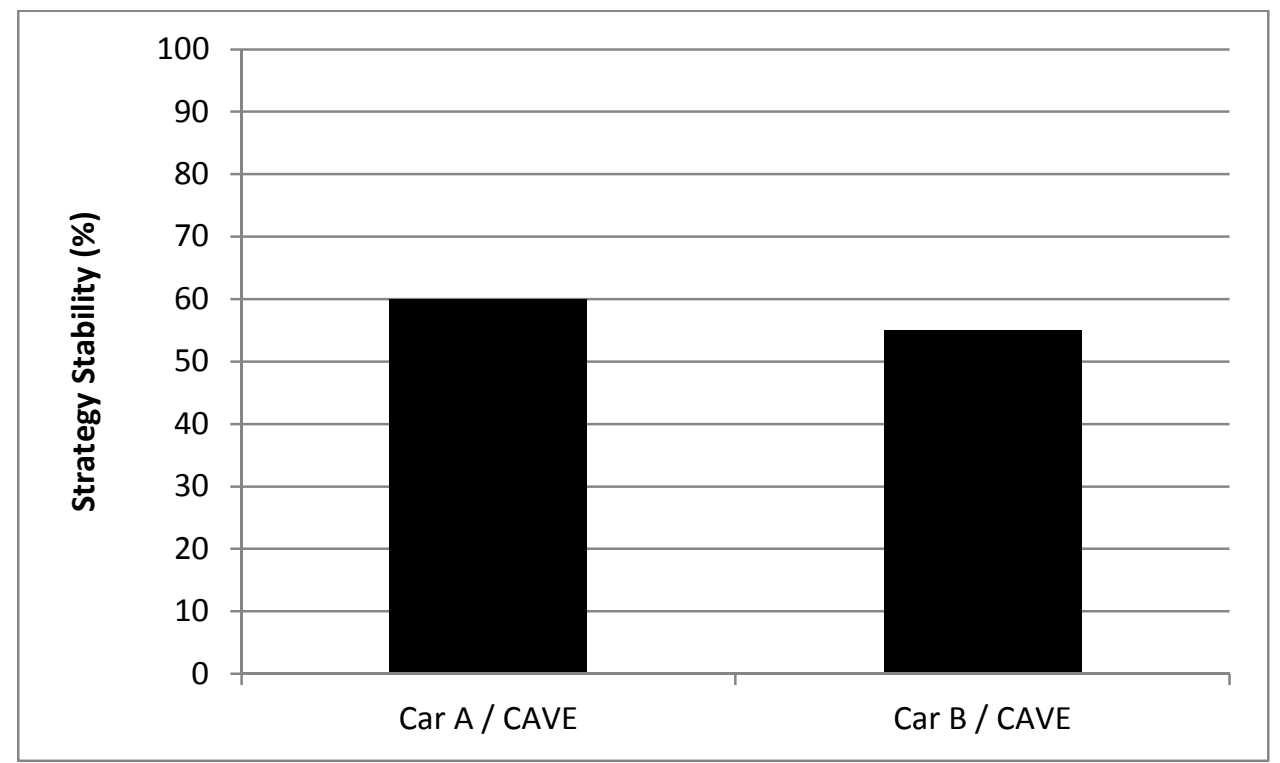

Figure 5 Percentage of participants who exhibited stability between the physical condition and CAVE for each vehicle.

\subsection{Discussion}

The stability of entry strategy within the physical vehicle, buck and virtual conditions shows participants responded to the cues provided to them in each condition and entered the vehicles accordingly. However, greater instability was seen across physical to virtual properties. Thus, we can hypothesise that the cues in the virtual environment are not representative of the cues on a physical vehicle and lead to a weaker understanding of the vehicle geometry being assessed, and hence inconsistency in the approach adopted by the participants. 
The high proportion of participants using the slip strategy supports the findings of Rigel (2005), where $80 \%$ of 225 participants adopted this strategy. This is greater than the percentages reported in comparable research. Ait al Menceur et al. (2008) classified the slip strategy as one-foot ingress movement with lateral sliding. In their study $51 \%$ of the participants adopted this strategy. This is due to the differences in participant samples. While the present study and Rigel (2005) did not use older adults or those with prostheses, they were included in the Ait al Menceur et al (2008) study and it was found that they were more likely to use a two-feet strategy aligned to the plump strategy.

The increase in use of the hurdle strategy in the CAVE conditions may be understood with reference to Rigel's (2005) work. Rigel (2005) explained that one of the main factors determining entry strategy is safety by avoidance of collision. Thus, participants in the physical property often used the slip strategy to most effectively avoid a head collision with the cant rail. In the virtual world, there was no risk of physical collision with the cant rail and therefore participants could adopt the hurdle strategy without risk of physical impact. It may also be that they wanted to look at the cant rail for as long as possibly in the virtual environment, which would necessitate a head movement towards the cant rail (due to limited field of view with the CAVE glasses) which in turn promoted the hurdle strategy. The collision avoidance explanation is supported by the work of Arlt (1998) who found that with a soft trim the safety distance during entry was less than with a harder trim.

\section{Study 2: Interviews with JLR stakeholders}

Study 1 provided data on the validity of the CAVE when designing for ease of entry and exit. However, other aspects relate to the success of a method (Wilson, 2005), including acceptance to stakeholders, in this case ergonomists and engineers responsible for optimising the ease of entry and exit on future vehicles. In Study 2, a questionnaire was designed and administered to understand stakeholders' perceptions of methods for optimising entry \& exit. This extended beyond study 1's focus on validity (although participants in Study 2 were asked to comment on their perceptions of the methods' validity 
i.e. face validity) to other practical aspects of using these methods in the automotive industry, such as identifying and communicating issues, informing design, and the costs and effort required to use each method. This information could only be obtained from experienced professionals from within the automotive industry.

Study 2 included the end users' views on the CAVE and buck properties evaluated in study 1, but also included other methods currently used or under consideration for use for optimising entry and exit. This range of methods was chosen because Study 1 demonstrated that the CAVE is unlikely to satisfy all entry and exit requirements if used as the sole design method. Thus, other methods, and quite possibly a combination of methods, are most likely to effectively optimise entry and exit. Given that each method requires some level of resource to implement, there may also be savings through the strategic and timely use of certain methods. Therefore, we also aimed to establish when in the vehicle development process each method should be used.

\subsection{Method}

\subsubsection{Participants}

A total of 10 stakeholders (9 male, 1 female) were recruited from JLR, made up of ergonomists and engineers. All stakeholders had some responsibility towards optimising entry and exit, including; manage delivery of entry and exit targets for vehicle programmes; setting entry and exit targets; entry and exit target validation and sign-off; responsibility for vehicle package; and running user trials. Mean age was 38.9 ( $S D=6.9$, range: $29-49)$. Participants had a mean of 3.4 years in their current post $(S D=2.1$, range $1-8)$ and a mean of 13.1 years in the automotive industry $(S D=11.9$, range $1-34)$.

\subsubsection{Materials}

Definitions of entry and exit methods which were provided to participants are shown in Figure 6. The methods were chosen based on current methods used, or methods under consideration for use, at JLR. 
1. CAD reviews. This can be considered as a form of digital benchmarking, in which CAD drawings of competitor \& current cars are analysed with consideration given to entry and exit.

2. Benchmarking (competitor cars). This is an experiential approach, in which people try entry and exit on a selection of actual competitor vehicles.

3. Benchmarking (internal reviews). Another experiential approach, but in this one people try entry and exit on one or more of JLR's current products.

4. Digital human modelling (DHM). Computer representations of people are used to analyse entry and exit on CAD. Popular DHM tools include RAMSIS and JACK.

5. Target buck*. This involves generating a buck which represents the target dimensions for a vehicle under development. It provides the experience of entry and exit based on the agreed targets.

6. Package buck trials. With this approach a buck is built to the design intent. This is then analysed by participants in a user trial.

7. Virtual reality CAVE trials. Entry and exit can be evaluated using a physical seating buck (i.e. seat, floor, pedals, and steering wheel) and 3D virtual representation of the rest of the vehicle geometry.

Figure 6. Description of each method for optimising vehicle entry and exit.

* The term "buck" is well-understood within the automotive industry, and did not require further explanation.

A questionnaire was developed to elicit participants' opinions towards the entry exit

methods. This required participants to rate the methods against the criteria shown in Figure

7. These were derived from established criteria on which to judge a human factors method

(e.g. Wilson, 2005) and also the purpose of entry and exit investigations within JLR.

Participants were also provided with space to make general comments about each of the methods.

1. This method is useful for identifying entry and exit issues

2. This method is useful for communicating entry and exit issues to the project team and to decision makers

3. This method is inexpensive to implement

4. This method is quick to implement

5. This method is easy to use / implement

6. This method has high validity (i.e. the results represent those obtainable from a real car) 
7. This method has high reliability (i.e. the results are repeatable)

8. This method can be used to inform the vehicle development process

Figure 7. Criteria against which each method was rated (on a 7-point Likert-style scale ranging from 1: strongly disagree to 7: strongly agree)

The second part of the questionnaire involved presenting participants with a list of the methods and various stages of the vehicle development cycle. This is shown in Figure 8. The stages of the vehicle development cycle/activities overlap but are broadly sequential in the order shown.

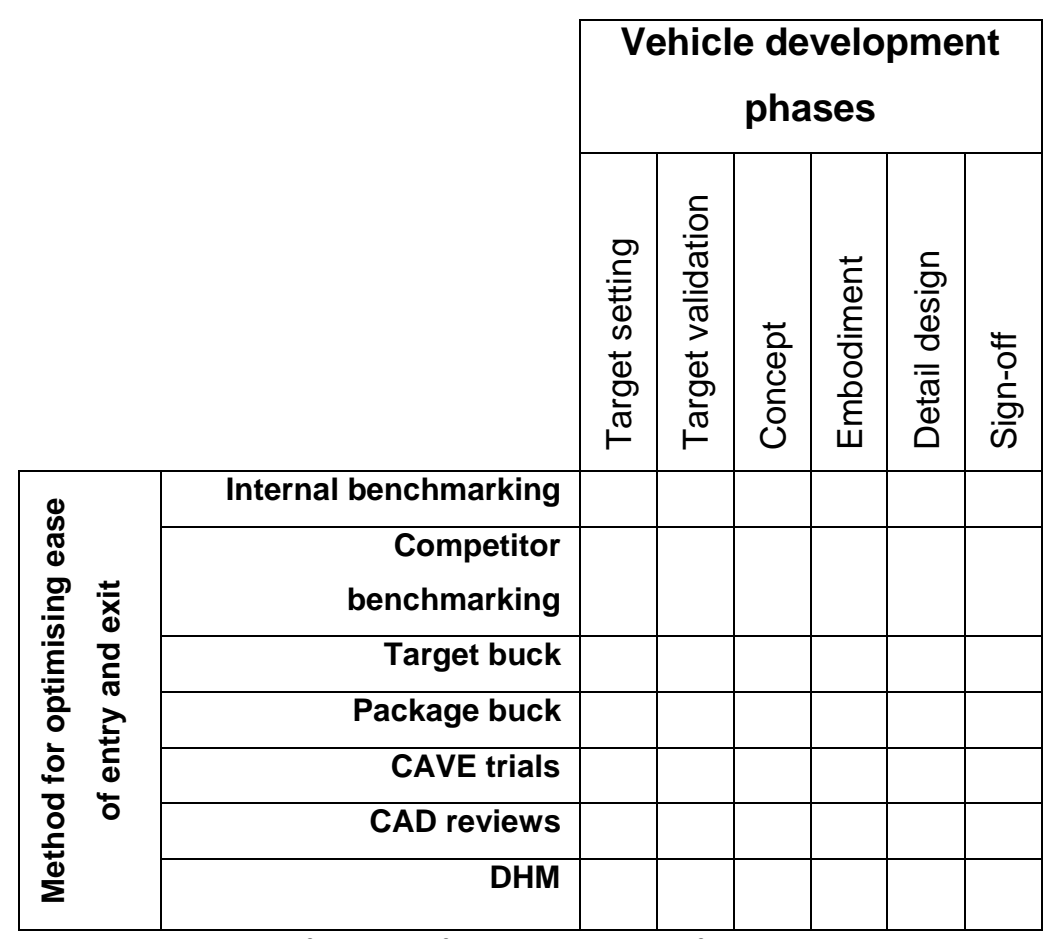

Figure 8. Usage of methods for various phases of vehicle development

\subsubsection{Procedure}

Participants were welcomed, given the participant info sheet, asked if they had any questions, and asked to complete demographics regarding their age, gender, current role, time in role, time in the automotive industry and responsibilities towards entry and exit. Thereafter, they were provided with the descriptions of each of the methods shown in Figure 6. The presentation order of the methods was determined through an incomplete balanced Latin square design. 
Participants were then asked to complete the questionnaire described above. For each method, they rated it against the criteria shown in Figure 7. They were also invited to make comments to support their ratings.

Finally, they were asked to indicate for which vehicle development phases they thought each method would be suitable, as shown in Figure 8 . They were told that they could tick more than one phase per method and that they did not have to tick any particular method for any particular phase.

The study received approval from The University of Nottingham Faculty of Engineering Ethics Committee.

\subsection{Results}

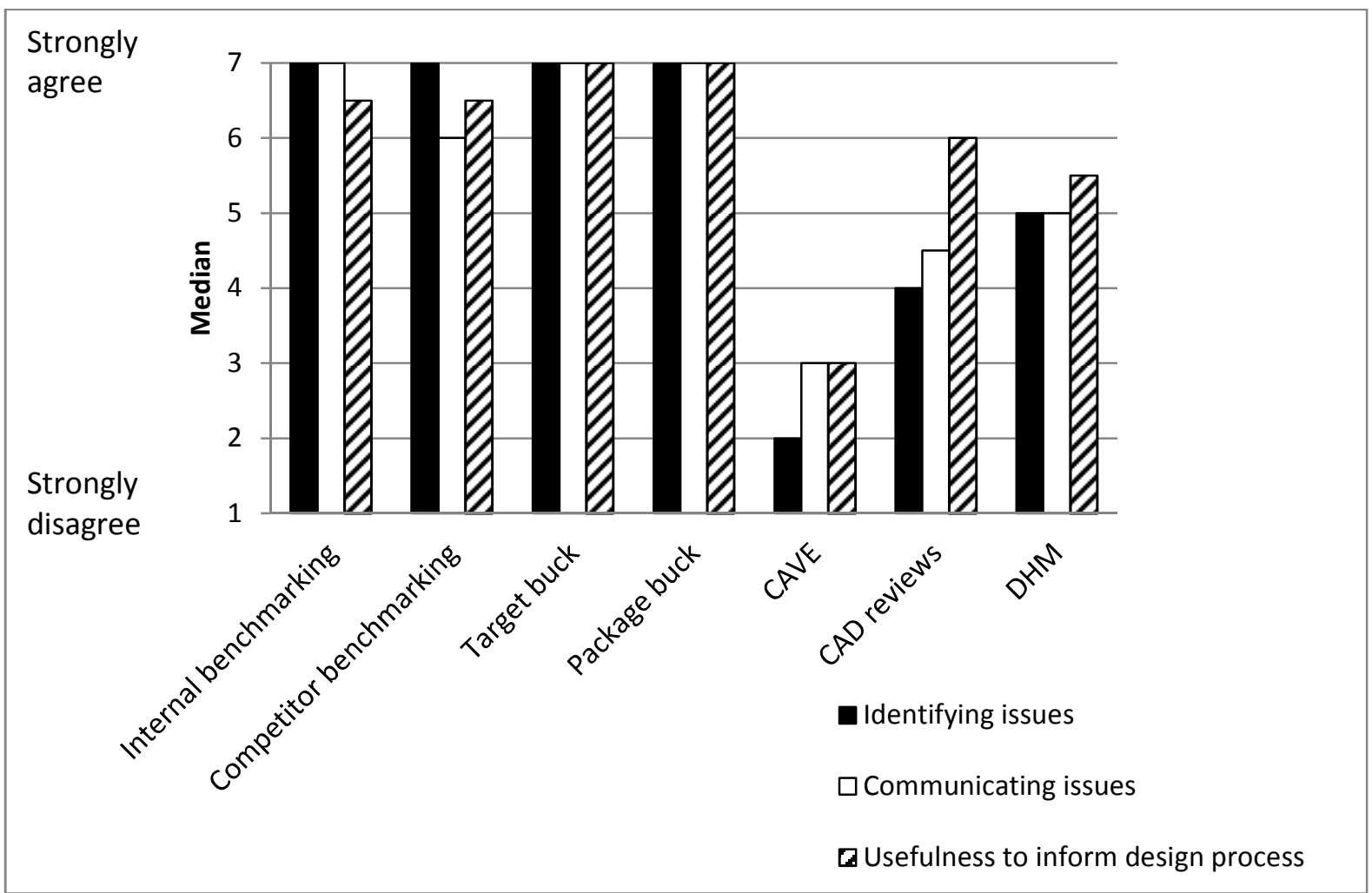

Figure 9. Median ratings for each of the seven methods for optimising ease of entry and exit. The ratings relate to aspects of the vehicle development process (identifying and communicating issues; informing the development process).

Median ratings for question 1, 2 and 8 are shown in Figure 9. These all relate to aspects of the vehicle development process. Ratings for "identifying issues" showed significant 
differences between the methods $\left(x^{2}=42.195, d f=6, p<0.001\right)$. Post-hoc analysis was conducted according to the mean rank differences methods described by Field (2009) based on Siegel and Castellan (1988) which addresses the concerns of over-caution of Bonferroni adjustment (Perneger, 1998). The post-hoc tests showed that the CAVE was perceived as less able to identify entry and exit issues than the physical methods (Internal Benchmarking $\bar{R}_{\mathrm{u}}-\bar{R}_{\mathrm{v}}=3.55$, Competitor Benchmarking $\bar{R}_{\mathrm{u}}-\bar{R}_{\mathrm{v}}=3.95$, Target buck $\bar{R}_{\mathrm{u}}-\bar{R}_{\mathrm{v}}=3.90$, and Package buck $\bar{R}_{\mathrm{u}}-\bar{R}_{\mathrm{v}}=4.65$; tested at $\mathrm{p}<0.05$; critical difference $=2.90$ ). $\mathrm{DHM}$ was perceived as less useful for identifying issues than the package buck $\left(\bar{R}_{\mathrm{u}}-\bar{R}_{\mathrm{v}}=3.25\right)$. No other significant differences were found, although the difference between CAD and the Package buck approached significance $\left(\bar{R}_{\mathrm{u}}-\bar{R}_{\mathrm{v}}=2.85\right)$.

A significant difference was found in the ratings for communicating issues $\left(x^{2}=44.357, d f=6\right.$, $p<0.001)$. The CAVE was perceived as less useful for communicating entry and exit issues than the physical methods (Internal Benchmarking $\bar{R}_{\mathrm{u}}-\bar{R}_{\mathrm{v}}=4.05$, Competitor Benchmarking $\bar{R}_{\mathrm{u}}-\bar{R}_{\mathrm{v}}=3.10$, Target buck $\bar{R}_{\mathrm{u}}-\bar{R}_{\mathrm{v}}=4.00$, and Package buck $\bar{R}_{\mathrm{u}}-\bar{R}_{\mathrm{v}}=4.40$; tested at $\mathrm{p}<0.05$; critical difference=2.90). CAD and DHM were also perceived as less useful for communicating issues than the package buck $\left(\bar{R}_{\mathrm{u}}-\bar{R}_{\mathrm{v}}=2.95\right.$ and $\bar{R}_{\mathrm{u}}-\bar{R}_{\mathrm{v}}=3.2$, respectively $)$.

Again, ratings for "usefulness to inform" differed significantly between methods $\left(x^{2}=32.107\right.$, $\mathrm{df}=6, \mathrm{p}<0.001)$. The CAVE was perceived as less useful than three of the physical methods (Competitor Benchmarking $\bar{R}_{\mathrm{u}^{-}} \bar{R}_{\mathrm{v}}=3.33$, Target buck $\bar{R}_{\mathrm{u}^{-}} \bar{R}_{\mathrm{v}}=3.67$, and Package buck $\bar{R}_{\mathrm{u}^{-}}$ $\bar{R}_{\mathrm{v}}=4.06$; tested at $\mathrm{p}<0.05$; critical difference $\left.=2.90\right)$. DHM was perceived as less useful for informing the development process than the package buck $\left(\bar{R}_{\mathrm{u}} \bar{R}_{\mathrm{v}}=3.11\right)$.

Thus, the physical methods, in particular the Package buck, are particularly strong for supporting the vehicle development process. CAD reviews and DHM may be useful during the early development stages, but concerns exist over entry and exit analysis without a 
dynamic indication of movement or without the experience of entry and exit. The CAVE was consistently weaker than the physical methods for identify issues, communicating issues, and informing the process, attributed to the lack of vehicle hard points (fixed physical elements of the car) experienced when entering or exiting a representation of a vehicle in the CAVE.

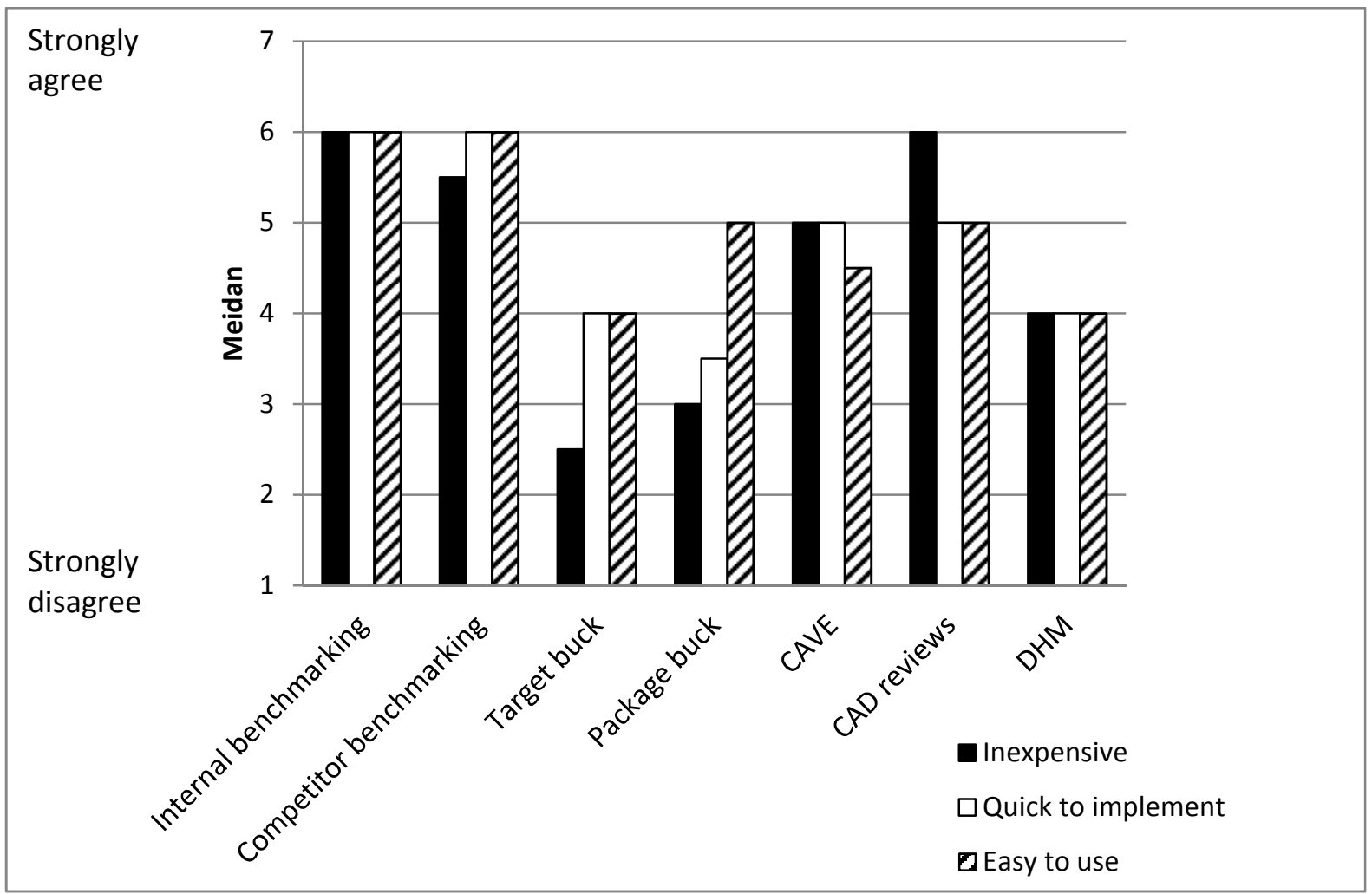

Figure 10. Median ratings for each of the seven methods for optimising ease of entry and exit. The ratings relate to logistics of implementing the methods. For clarity a higher rating is always more favourable (i.e. a median rating of 6 for "inexpensive" is cheaper than a median of 3).

The group of ratings in Figure 10 relate to questions associated with logistics of implementing the methods. Ratings for "inexpensive" differed between the methods $\left(x^{2}=\right.$ 32.371, $\mathrm{df}=6, \mathrm{p}<0.005)$. The target buck was perceived as more expensive than internal benchmarking $\left(\bar{R}_{\mathrm{u}^{-}} \bar{R}_{\mathrm{v}}=3.75\right)$, competitor benchmarking $\left(\bar{R}_{\mathrm{u}}-\bar{R}_{\mathrm{v}}=3.15\right)$, or CAD reviews $\left(\bar{R}_{\mathrm{u}^{-}}\right.$ $\left.\bar{R}_{\mathrm{v}}=3.70\right)$. The package buck was perceived as more expensive than internal benchmarking $\left(\bar{R}_{\mathrm{u}}-\bar{R}_{\mathrm{v}}=3.25\right)$, and CAD reviews $\left(\bar{R}_{\mathrm{u}}-\bar{R}_{\mathrm{v}}=3.20\right)$. 
Significant differences existed for "quick to implement" $\left(x^{2}=23.296, d f=6, p=0.001\right)$. The post-hoc tests revealed that the only differences were that the target buck was less quick to implement than internal benchmarking $\left(\bar{R}_{\mathrm{u}}-\bar{R}_{\mathrm{v}}=3.167\right)$ and CAD reviews $\left(\bar{R}_{\mathrm{u}}-\bar{R}_{\mathrm{v}}=3.278\right)$.

Differences also existed for "easy to use" $\left(x^{2}=18.710, d f=6, p=0.005\right)$. The only significant post hoc difference was that competitor benchmarking is easier than $\mathrm{DHM}\left(\bar{R}_{\mathrm{u}} \bar{R}_{\mathrm{v}}=3.167\right)$.

Participants' comments supported these ratings, reporting that there is a cost and time associated with building bucks; benchmarking and CAD reviews were perceived as cheaper. However, some concerns were raised about the availability of vehicles for benchmarking.

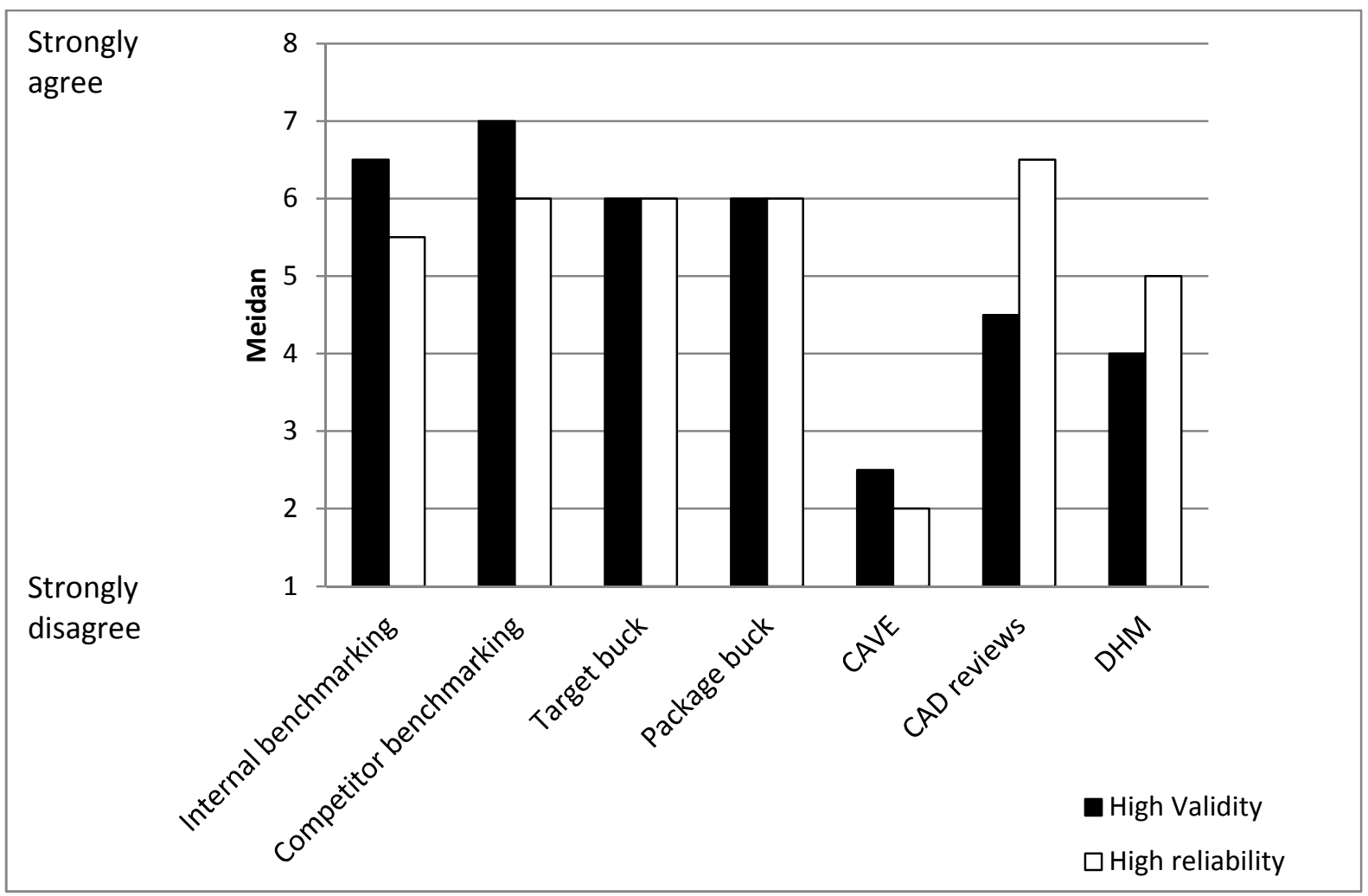

Figure 11. Median ratings for each of the seven methods for optimising ease of entry and exit. The ratings relate to the validity and reliability of the methods.

The ratings in Figure 11 relate to the validity and reliability of the methods. Validity differed between the methods $\left(x^{2}=30.460, d f=6, p<0.001\right)$. The CAVE was perceived as less valid than internal benchmarking $(\bar{R} \mathrm{u}-\bar{R} \mathrm{v}=4.000)$, competitor benchmarking $\left(\bar{R}_{\mathrm{u}}-\bar{R}_{\mathrm{v}}=4.111\right)$, and 
the package buck $\left(\bar{R}_{\mathrm{u}} \bar{R}_{\mathrm{v}}=3.722\right)$. Competitor benchmarking was also perceived as more valid than digital human modelling $\left(\bar{R}_{\mathrm{u}}-\bar{R}_{\mathrm{v}}=2.944\right)$. Reliability also differed $\left(\mathrm{x}^{2}=21.505, \mathrm{df}=6\right.$, $\mathrm{p}=0.001)$. CAVE was perceived as less reliable than competitor benchmarking $\left(\bar{R}_{\mathrm{u}^{-}}\right.$ $\left.\bar{R}_{\mathrm{v}}=3.167\right)$, Package buck $\left(\bar{R}_{\mathrm{u}}-\bar{R}_{\mathrm{v}}=3.556\right)$, and CAD $\left(\bar{R}_{\mathrm{u}}-\bar{R}_{\mathrm{v}}=3.889\right)$.

Internal benchmarking, competitor benchmarking and the package buck were commented on as valid methods for studying entry and exit, providing the selection of cars (or the buck) represented the design intent. Participants mentioned that a robust method and skilled operator is essential for reliable assessment with DHM. Concerns reported earlier about the inability of the CAVE to represent vehicle hard points also apply to its validity.

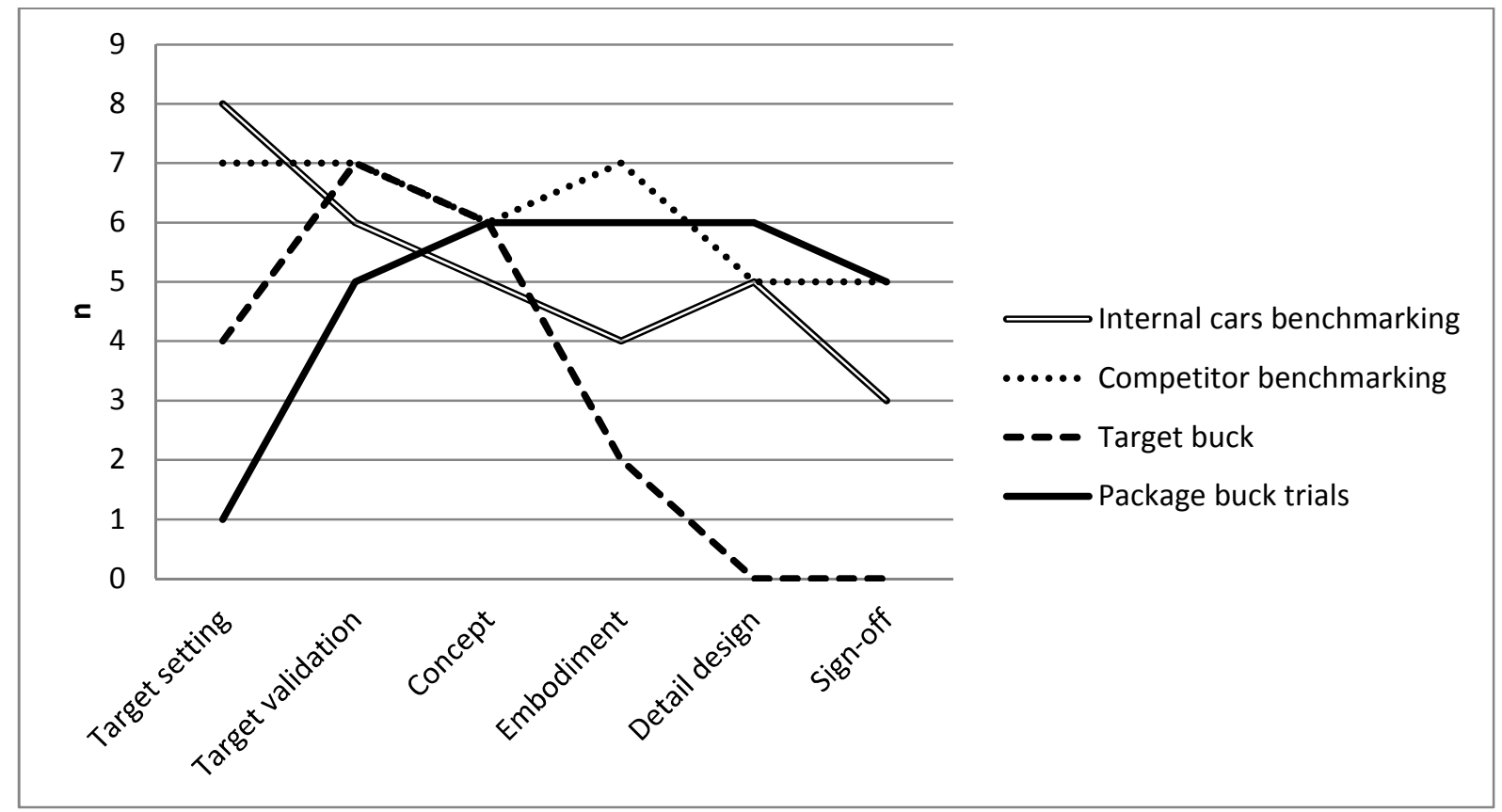

Figure 12. Number of times each method was deemed suitable for each activity (physical methods) 


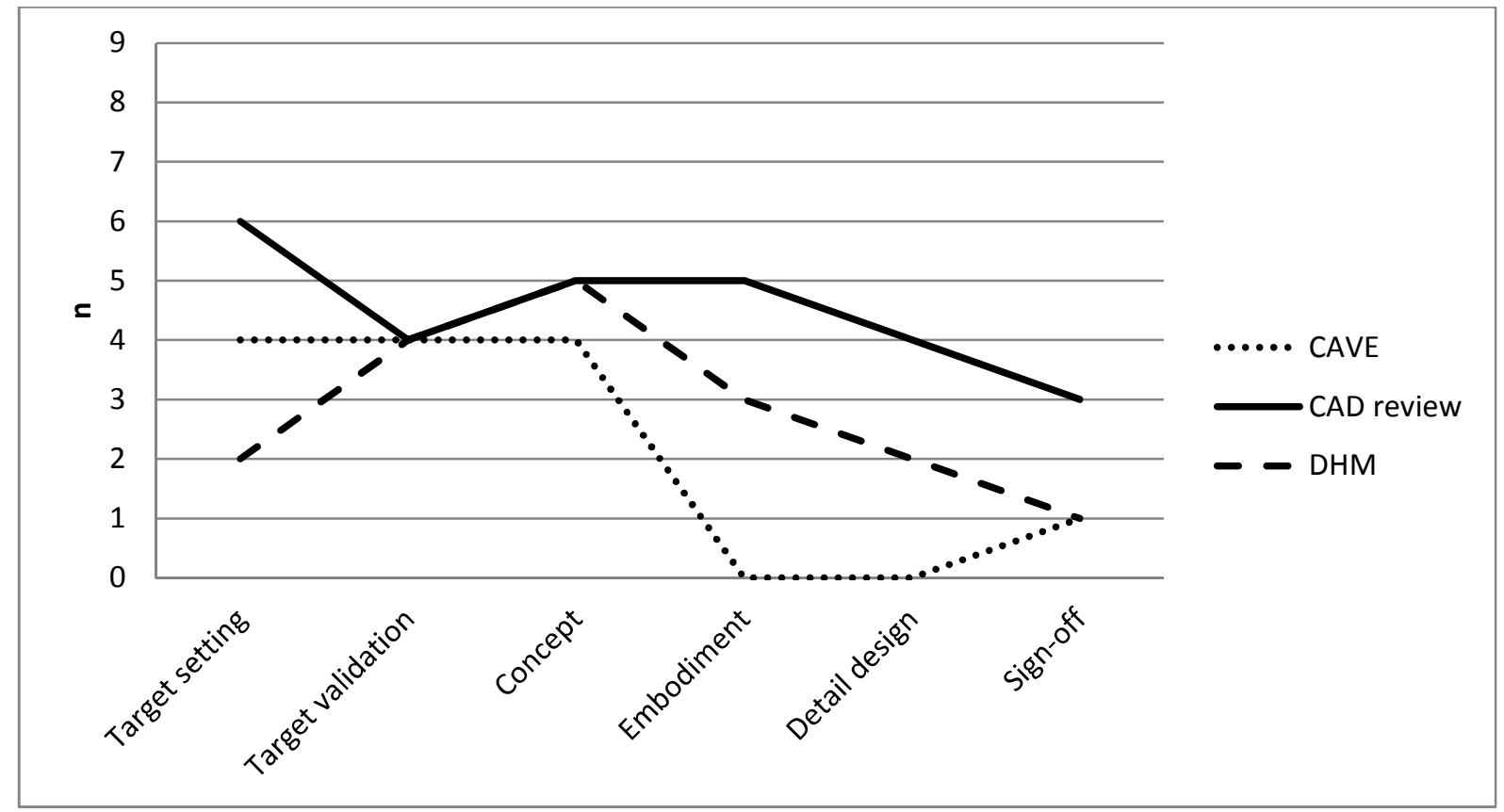

Figure 13. Number of times each method was deemed suitable for each activity (digital/combination methods)

Figures 12 (physical methods) and 13 (digital/combination methods) show the number of participants who thought that each method would be suitable for use at various stages of the vehicle development.

Cochran's $Q$ test showed significant differences between the data for target setting $(\mathrm{Q}=18.955, \mathrm{df}=6, \mathrm{p}=0.004)$. As post hoc testing required 21 pairs of comparisons with McNemar's test, Bonferroni became highly conservative $(0.05 / 21=0.0024)$, with no pairs showing significance. Furthermore, the method used before for multiple comparisons does not apply to dichotomous data. Therefore, it was decided that an appropriate compromise between stringency and the risk of type 1 error would be to look for significance at $p<0.01$. However, none of the individual tests demonstrated significance, with only the difference between the Package buck and Internal benchmarking approaching significance $(\mathrm{N}=8$; $p=0.016)$. 
Target validation showed no significant differences between the methods $(\mathrm{Q}=6.316, \mathrm{df}=6$, $p=0.389$ ). There was also no difference between use of the methods during the concept phase $(\mathrm{Q}=2.118, \mathrm{df}=6, \mathrm{p}=0.909)$.

There was a significant difference between the methods for the embodiment phase $(Q=18.769, d f=6, p=0.005)$. The post hoc testing with McNemar's test at $p<0.01$ showed that the only difference approaching significance was between competitor benchmarking and the CAVE $(\mathrm{N}=8, \mathrm{p}=0.016)$.

Differences also existed at the detail design phase $(\mathrm{Q}=19.350, \mathrm{df}=6, \mathrm{p}=0.004)$. While none of the post hoc comparisons with McNemar's reached significance, the differences which most closely approached significance were Target buck and package buck ( $N=8, p=0.031$ ) and Package buck and CAVE $(\mathrm{N}=8, \mathrm{p}=0.031)$.

Differences were also seen between the methods for sign off $(Q=12.769, d f=6, p=0.047)$. The post hoc comparisons which most closely approached significance was target buck and package buck $(\mathrm{N}=8, \mathrm{p}=0.063)$.

\section{Discussion}

This research has shown that while people are consistent in the entry strategies adopted in a buck, a production car and a CAVE, they were inconsistent between a production car and a CAVE, or buck and a CAVE. This difference suggests that the CAVE cannot currently provide a valid indication of ease of entry, and thus should not be used in this way to support design for ease of entry. As highlighted in the introduction, entry and exit are complex interactions with the car, but entry is one of the first consumer experiences and it is important that the design method used is valid to achieve this. Moreover, use of an invalid method at the design stage could lead to late changes once physical prototypes become 
available, particularly as entry and exit is reliant upon the fundamental geometry of the vehicle package. Therefore, these changes are likely to be significant and costly.

Moreover, for optimising entry and exit, physical methods are generally perceived as being better than digital methods by JLR stakeholders. That is, the physical methods are viewed as being more reliable, have higher validity and are considered to be good at identifying and communicating issues and useful to inform the design process.

However, physical methods also have issues - for example there is a time and cost associated with building bucks which is less for the virtual methods. This time penalty of physical bucks is in conflict with the industry aim to reduce development times. Thus, it is understandable that there is motivation to make greater use of virtual technologies. However, while the CAVE has great use in other applications in the vehicle development process (e.g. all round vision, driving simulation) it is not appropriate in its current form for experiential entry and exit analysis. The stakeholders' primary concern with the CAVE was lack of hard points. Thus, it may currently be limited to uses other than providing the experience of entry exit from a customer's perspective, for example design reviews of 3D overlays of various A-pillars between vehicles. .

There may however be opportunities for developing the CAVE for use in entry exit analysis. For example, the effect of graphics quality on distance perception has been recognised as an open area requiring more research (Kenyon et al., 2007; Renner et al., 2013). Renner et al. (2013) emphasise the importance of a virtual environment with a ground texture, as the "compression" of texture at further distances can be an important cue (Renner et al., 2013). Murgia and Sharkey (2009) found that the underestimation of depth was less in a rich virtual environment with textured background surfaces. Similarly, Kenyon et al. (2007) found improvements in size constancy (the ability to perceive objects of the same size at a variety of distances) in richer virtual environments with surrounding objects providing depth cues. Hu et al. (2000) found improvements from the use of shadows and object inter-reflections in 
participants' ability to judge imminent contact between virtual objects. It may be that greater use of cues such as these could improve depth perception in the CAVE. Bouguila et al. (2000) found that providing force feedback helped improved depth perception in a stereoscopic virtual environment. The force was implemented by strings from motors which acted at certain depths, corresponding to virtual objects. Swapp et al. (2006) also demonstrated improvements in spatial accuracy and spatial response tasks for a PC-based co-located device with haptic feedback. Obviously these systems would need developing to be suitable for entry and exit, but the same principle of combining visual and haptic feedback may be worth investigation, particularly to address the lack of hard points in the CAVE.

However, none of the above will address issues of occlusion; the virtual components will appear behind the physical components regardless of their distance from the viewer in the real world. An alternative approach might be to consider different mixed reality systems such as a see-through head-mounted display (HMD) (e.g. Rolland and Hua, 2005). Gao et al. (2012) report developments on a light-weight occlusion-capable HMD system, but the suitability of this for entry and exit would need testing as HMD systems have been reported to cause ergonomics issues (Nichols, 1999) and even the use of a light-weight device may influence the entry or exit task. Moreover, depth perception issues have been reported in augmented reality systems (Singh et al., 2010) and HMDs tend to have limited field of view (Zhou, 2008), which is likely to influence the entry and exit tasks.

As mentioned, physical bucks are not without fault; this study corresponded with the previously established time and cost penalty associated with physical prototypes (Laughery, 2005) and therefore any method which reduces this is worthy of investigation. DHM may offer some value within the development process, but the stakeholders were generally more positive about experiential methods as they were deemed to be more capable in identifying issues, communicating issues, and informing the process, attributed to their vehicle hard points (fixed physical elements of the car) experienced when entering or exiting. Study 1 indicated that the vehicle geometry has a greater impact than the appearance of the 
property, as the seating buck evaluated was very obviously a buck; it did not have the level of trim or finish of a production car. Thus, it may be that the ideal method combines the flexibility to quickly review, and modify, several designs afforded by virtual prototyping with the actual experience and hardware provided by physical bucks. For example, in recent years many developments have been made in rapid prototyping. As the costs of these reduce, and the capability to prototype large-scale products increases, it may be possible to prototype design intent nearly immediately.

It must be recognised that the stakeholders in this study were limited to one automotive company. Thus, their perceptions may be influenced by company policy or the availability and use of methods within that organisation. Related to this, participants were less familiar with DHM than the other methods. Therefore, their perceptions of this method should be treated with caution.

A possible limitation of study 1 is the use of left hand drive properties which would be less familiar to the participants than the more commonly used right hand drive in the UK. As an international company, left hand drive is the norm for engineering development and bucks at Jaguar Land Rover, and employees are familiar with left hand drive properties. While right hand drive properties would have been preferable, a right hand drive buck was not available, and it was considered that consistency was of greater importance hence the use of left hand drive throughout.

\section{Recommendations}

Based on the findings of this study, we are able to create recommendations for the use of tools in the automotive design process for entry and exit development and validation by vehicle development stage.

There is no single tool that has a high level of acceptability at each stage of the vehicle development process. It is clear therefore that a suite of tools need to be used in the development process. 


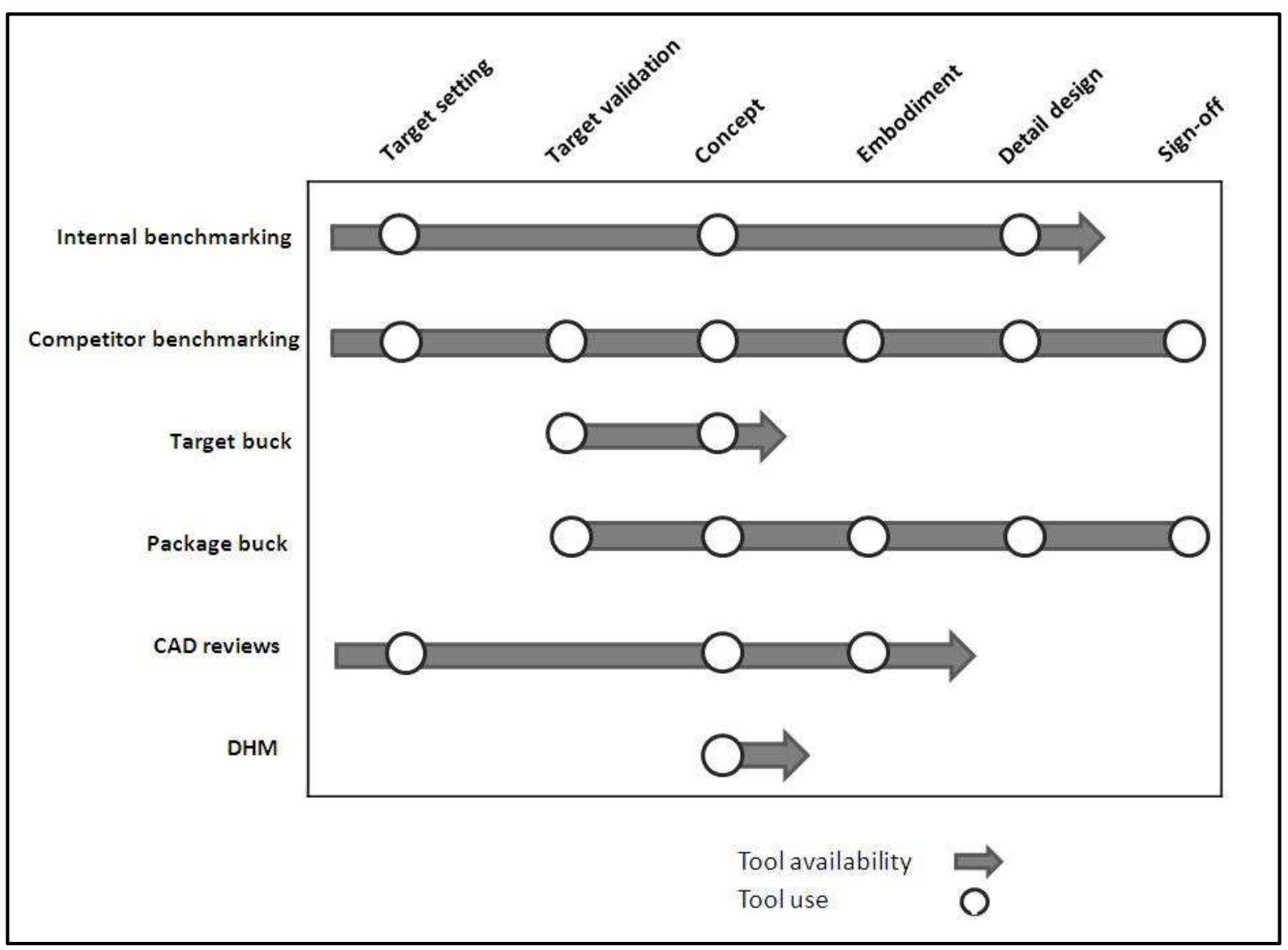

Figure 14 Tool availability and use in the Vehicle Development Process

The following tools are therefore recommended at these stages of the vehicle development process:

- Target setting - Benchmarking of internal cars and competitors, supported by CAD reviews. Training and experience is required for assessing CAD images.

- Target validation - The target buck and competitor benchmarking supported by the package buck. The target buck must be accurate in order to be effective.

- Concept - A combination of all the tools, with the exception of the CAVE. For DHM to be effective training and experience is required.

- Embodiment - Competitor benchmarking and package buck, supported by CAD review. 
- Detail design - The package buck supported by benchmarking of internal and competitor vehicles.

- Sign-off - package buck trials backed with a competitor vehicle for comparison purposes.

The CAVE is not currently recommended for use in assessment of entry and exit. However, future developments of a virtual environment that include physical cues or physical feedback may address these issues. Further research work is needed in this area.

\section{Conclusions}

This study has shown that a physical representation of a design (a buck) can yield consistent and valid entry strategies, which were not observed in a CAVE 3D immersive environment. This was attributed to the lack of physical geometry in the CAVE which is present in bucks and in real cars. Industry stakeholders from an automotive company also rated the CAVE worse than physical methods for identifying entry and exit issues, and having lower perceived validity and reliability than physical methods. The digital methods were in general weaker for communicating issues, indicating the importance of the experience of entry and exit for supporting the design process. However, there is a time and cost associated with building bucks. To best optimise entry and exit various combinations of methods are required at different stages of the vehicle development process. While the CAVE has proven use in other applications (e.g. driving simulators, exterior vision) it requires development before it can be used to provide the customer experience of entry and exit.

\section{Acknowledgments}

The authors would like to acknowledge Brian Waterfield of the Jaguar Land Rover Virtual Innovation Centre for the support given to study 1 . 


\section{References}

Ait El Menceur, M. O., Pudlo, P., Gorce, P., Thevenon, A., \& Lepoutre, F. 2008. Alternative movement identification in the automobile ingress and egress for young and elderly population with or without prostheses. International journal of industrial ergonomics, 38, 1078-1087.

Andreoni , G., Rabuffetti, M., \& Pedotti, A. 2004. Kinematics of head movements while entering and exiting a car. Ergonomics, 47(3), 343-359.

Annett, J. 2002. A note on the validity and reliability of ergonomics methods. Theoretical Issues in Ergonomics Science, 3(2), 228-232.

Arlt, F 1998. Untersuchung zielgerichteter Bewegungen zur Simulation mit einem CADMenschmodell. Dissertation, Lehrstuhl für Ergonomie, Technische Universität München, Munich.

Baitch, L \& Smith, R.C. 2000. Physiological correlates of spatial perceptual discordance in a virtual environment. In: Proceedings of the Fourth International Projection Technology Workshop, Ames, lowa, 2000.

Bernard, A.,Daaboul, J., Laroche, F., and Cunha, D. 2012. Mass Customisation as a Competitive Factor for Sustainability. Enabling Manufacturing Competitiveness and Economic Sustainability 2012, Part 1, 18-25.

Bhise, V. D. 2011. Ergonomics in the automotive design process. Boca Raton: CRC Press.

Bouguila, L., Ishii, M., Sato, M. 2000 Effect of coupling haptics and stereopsis on depth perception in virtual environment. Proceedings of the $1^{\text {st }}$ Workshop on Haptic Human Computer Interaction. $31^{\text {st }}$ August $-1^{\text {st }}$ September 2000 .

Causse, J., Wang, X., \& Denninger, L. 2012. An experimental investigation on the requirement of roof height and sill width for car ingress and egress. Ergonomics, 55 (12), 1596-1611.

Chateauroux, E., \& Wang, X., 2010. Car egress analysis of younger and older drivers for motion simulation. Applied Ergonomics, 42, 169-177.

Chen, J., Zhou, J., Sun, J. 2013. Visual discomfort induced by adjustment of convergence distance in stereoscopic video. In: Broadband Multimedia Systems and broadcasting (BMSB) IEEE, London, 5-7 June 2013, pp 1-5.

Cherednichenko, A., Assman, E., \& Bubb, H. 2006. Computational approach for entry simulation. SAE Technical Paper Series. 2006-01-2358.

Cruz-Neira, C., Sandin, D. J., DeFanti, T., Kenyon, R. W., \& Hart, J. C. 1992. The cave. Audio visual experience automatic virtual environment. Communications of the ACM, 35(6), 64-72. 
Drascic, D., and Milgram, P. 1996. Perceptual Issues in Augmented Reality. Proceedings of SPIE Vol. 2653. Stereoscopic Displays and Virtual Reality Systems III, San Jose, California, Feb 1996, pp 123-134.

Dufour, F., \& Wang, X. 2005. Discomfort assessments of car ingress/egress motions using the concept of neutral movement. SAE Technical Paper Series. 2005-01-2706.

Dymott, R., Janes, B., Harker, S., Scheuchenpflug, R., Ruspa, C., and Quattrocolo, S. 2003. Older drivers in Virtual Reality assessment of vehicle ergonomics. In: D de Waard, K.A. Brookhuis, S.M. Sommer, W.B. Verwey (Eds) Human Factors in the Age of Virtual Reality. Maastricht, the Netherlands: Shaker Publishing.

Field, A. 2009. Discovering Statistics Using SPSS (3 ${ }^{\text {rd }}$ Ed). London: SAGE publications.

Gao, C., Lin, Y., \& Hua, H. 2012. Occlusion Capable Optical See-through Head-Mounted Display Using Freeform Optics. In: Mixed and Augmented Reality (ISMAR) IEEE, 5-8 Nov 2012, Atlanta GA, 281-282.

Gransitzki K., 1994. Biomechanics of entering a car. Second International Congress on Physiological Anthropology, University of Kiel, Germany, September 12-16.

Häkkinen, J., Pölönen, M., Takatalo, J., Nyman, G. 2006. Simulator sickness in virtual display gaming: a comparison of stereoscopic and non-stereoscopic situations. MobileHCl'06, ACM, Helsinki, Finland, September 12-15.

Hanson, L., Blome, M., Dukic, T., Ho, D., Berg, G. 2006. Guide and documentation system to support digital human modelling applications. International Journal of Industrial Ergonomics, 36, 17-24.

Herriotts, P. \& Johnson, P. 2013. Are you sitting comfortably? A guide to occupant packaging in automotive design. In N.Gikkas (ed). Automotive Ergonomics: Driver-Vehicle Interaction (p. 17-39). Boca Raton: CRC Press.

Herriotts, P. 2005. Identification of vehicle design requirements for older drivers. Applied Ergonomics, 36 (3), 255-262.

Hu, H.H., Gooch, A.A., Thompson, W.B., Smits, B.E., Riser, J.J., Shirley, P. 2000. Visual cues for imminent object contact in realistic virtual environments. Proceedings IEEE Visualization, October 2000, 179-185.

IJsselsteijn, W.A., de Ridder, H., Vliegen, J. (2000). Effects of stereoscopic filming parameters and display duration on the subjective assessment of eye strain. In: J.O. Merritt, S.A. Benton, A.J. Woods, M.T. Bolas (Eds.), Stereoscopic Displays and Virtual Reality Systems VII, The International Society for Optical Engineering, Bellingham, WA (2000), pp. 12-22 
Jayaram, S., Vance, J., Gadh, R., Jayaram, U., Srinivasan, H. 2001. Assessment of VR technology and its applications to engineering problems. Journal of Computing and Information Sciences in Engineering, 1(2001), 72-83.

Johansson, L. 2002. Car ingress and egress: verification and evaluation of dimensions relevant for ergonomic comfort. MSc Thesis, Lulea University of Technology, Sweden.

Juan M.C., \& Perez, D. 2009. Comparison of the levels of presence and anxiety in an acrophobic environment viewed via HMD or CAVE. Presence, 18(3), 232-248.

Kawachi, K., Aoki, K., Mochimaru, M., and Kouchi, M. 2005. Visualization and Classification of Strategy for Entering Car. SAE Technical Paper. 2005-01-2683.

Kenyon, R.V., Sandin, D., Smith, R.C., Pawlicki, R., Defanti, T. 2007. Size-Constancy in the CAVE. Presence, 16(2), 172-187.

Kim, J., Matsui, Y., Hayakawa, S., Suzuki, T., Okuma, S., \& Tsuchida, N. 2005. Acquisition and Modeling of Driving Skills by Using Three Dimensional Driving Simulator. IEICE TRANSACTIONS on Fundamentals of Electronics, Communications and Computer Sciences (E88-A) 3, 770-778.

Klein, E., Swan, J.E., Schmidt, G.S., Livingston, M.A., Staadt, O. 2009. Measurement Protocols for Medium-Field Distance Perception in Large-Screen Immersive Displays. IEEE Virtual Reality 2009, 14-18 March, Lafayette, Louisiana, USA.

Koester, D. and Hamilton, R. 1994. A Methodology for Evaluating Barriers and Aids to Vehicle Ingress/Egress. SAE Technical Paper 940388, 1994, doi:10.4271/940388.

Laughery, R. 2005. Simulation and modelling for analysing human performance. In: J.R. Wilson, and N. Corlett, (Eds.), Evaluation of Human Work. 3rd ed. London: Taylor \& Francis, 219-238.

Lorenz, S., Kaiser, R., Assmann, E., Engstler, F., Zollner, R. 2008. Mixed reality for use in ergonomic car design: effect of different procedures on the seating position. Ergonomieabsicherung im Fahrzeug mittels Mixed Reality, 2008(62), 3-14.

Mollenhauer, M.A., Romano, R.A., and Brumm, B. 2004. The Evaluation of a Motion Base Driving Simulator in a CAVE at TACOM, 24th Army Science Conference, Orlando, Florida, December, 2004.

Monnier, G., Renard, F., Chameroy, A., Wang, X. \& Trasbot, J., 2006. A motion simulation approach integrated into a design engineering process. SAE International. Digital Human Modeling for Design and Engineering Conference. Lyon, France July 4-6, 2006.

Murgia, A., Sharkey, P.M. 2009. Estimation of Distances in Virtual Environments Using Size Constancy. The International Journal of Virtual Reality, 8(1), 67-74. 
Nichols, S. 1999. Physical ergonomics of virtual environment use. Applied Ergonomics 30(1999), 7990.

Olsson, P., Nysjo, F., Seipel, S. Carlbom, I. 2012. Physically co-located haptic interaction with 3D displays. IEEE Haptics Symposium 2012, Vancouver, BC, Canada March 4-7, 2012.

Perneger, T.V. 1998. What's wrong with Bonferroni adjustments. British Medical Journal, 216(7139), 1236-1238

Pudlo, P., Lempereur, M., Lepoutre, F., \& Gorce, P 2006. Prediction of the car entering motion. SAE Technical Paper Series. 2006-01-2357.

Rebelo, F., Duarte, E., Noriega, P., \& Soares, M. M. 2010. Virtual Reality in Consumer Product Design: Methods and Applications. In: Karwowski, W., Soares, M. M., Stanton, N. A. Ed. Human Factors and Ergonomics in Consumer Product Design: Methods and Techniques. pp. 381-402. Boca Raton: CRC Press.

Reed, M. P., \& Huang, S. 2008. Modelling vehicle ingress and egress using the human motion simulation framework. SAE Technical Paper Series. 2008-01-1896.

Renner, R.S., Velichkovsky, B.M., Helmert, J.R. 2013. The Perception of Egocentric Distances in Virtual Environments - A Review. ACM Computing Surveys, 46(2), pp. 23:1-23:40

Repperger D.W., Gilkey, R.H., Greeen, R., LaFleur, T., Haas, M.W. 2003. Effects of haptic feedback and turbulence on landing performance using an immersive cave automatic virtual environment (CAVE). Perceptual and motion skills, 3(1), 820-832.

Reuding, T., \& Meil, P. 2004. Predictive Value of Assessing Vehicle Interior Design Ergonomics in a Virtual Environment. Journal of computing and information science in engineering, 4, 109-113.

Rigel, S. 2005. Entwicklung und Validierung einer Methode zur quantitativen Untersuchung der Einund Ausstiegsbewegung in einen Pkw. Dissertation Technischen Universität München.

Roland, J., \& Hua, H. Head-mounted displays. 2005. Encyclopedia of Optical Engineering (2005), 113.

Schrader K. Remlinger, W. Meier, M. 2002. Mixed Reality with RAMSIS. Presented at SAE Digital Human Modeling Conference. München 2002.

Seron, F. J., Gutierrez, D., Magallon, J. A., Sobreviela, E. J., \& Gutierrez, J. A. 2004. A CAVE-like environment as a tool for full-size train design. Virtual Reality, 7(2), 82-93.

Siegel and Castellan Söderman, M. 2005. Virtual Reality in Product Evaluations with Potential Customers: An Exploratory Study Comparing Virtual Reality with Conventional Product Representations. Journal of Engineering Design, 16 (3), 311-328. 
Siegel, S., and Castellan, N.J. 1988. Nonparametric statistics for the behavioral sciences (2nd Ed.). New York, NY:McGraw-Hill.

Singh, G., Swan II, J.E., Jones, J.A., Ellis, S.R. (2010). Depth judgement measure and occluding surfaces in near-field augmented reality. Proceedings of ACM SIGGRAPH applied Perception in Graphics and Visualization (APGV2010), 149-156.

Sternini, D. and Cerrone, M. 1995. Set-up of an experimental procedure for measuring the human body movements when entering and exiting the vehicle, in L. Francione (ed.), Proceedings of Third International Conference on Vehicle Comfort and Ergonomics, pp 257-265. Bologna: Associazione Tecnica dell'Automobile.

Swapp, D., Pawar, V., Losco, C. 2006. Interaction with co-located haptic feedback in virtual reality. Virtual Reality, (2006), 10, 24-30.

Tetlock, P.E. 1983. Accountability and the perseverance of first impressions. Social Psychology Quarterly, 46, 285-292.

Wang, G.G. 2002. Definition and Review of Virtual Prototyping. ASME Journal of Computing and Information Science in Engineering, 2 (3), pp. 232-236.

Whalstrom, M., Aittala, M., Kotilainen, H., Yli-Karhu, T., Porkka, J., Nykanen, E. 2010. CAVE for collaborative patient room design. Virtual Reality, 14(3), 197-211.

Wilson, J. R. 2005. Methods in the understanding of human factors. In: J.R. Wilson, and N. Corlett, (Eds.), Evaluation of Human Work. 3rd ed. London: Taylor \& Francis, 1-31.

Zhan, J. Porter, M. M, Polgar, J. \& Vrkljan, B. 2013. Older drivers' opinions of criteria that inform the cars they buy: A focus group study. Accident analysis \& prevention, 281-287.

Zhou, F., Duh, H.B.L., \& Billinghurst, M. 2008. Trends in augmented reality tracking, interaction and display: A review of ten years of ISMAR. In: Proceedings of the 7th IEEE/ACM International Symposium on Mixed and Augmented Reality . IEEE Computer Society, 193-202 